\title{
Türkiye'de Tıbbi Dokümantasyon ve Sekreterlik Eğitiminin İncelenmesi, Mesleki Uygulamalar
}

\author{
Aslan KAPLAN Aysel KÖKSAL ${ }^{2}$ \\ ${ }^{1}$ Hacettepe Üniversitesi Sağllk Hizmetleri Meslek Yüksekokulu, Ankara, Türkiye \\ ${ }^{2}$ Ankara Üniversitesi Sağllk Hizmetleri Meslek Yüksekokulu, Ankara, Türkiye
}

Sorumlu Yazar: kaplan.aslan@gmail.com

\begin{abstract}
Özet
İletişim ve bilgi / belge kavramları birbirini tamamlayan ve birbirinden ayrılmayan önemli kavramlardır. (Tibbi sekreterliğin temel görev alanlarındandır.)Belgelerden verimli şekilde yararlanılabilmesi için; belgelerin bilimsel ilke ve kurallara göre; toplanması, düzenlenmesi, saklanması ve tekrar hizmete sunulması gerekir. Yani dokümantasyon faaliyetlerine tabi tutulması gerekir. Tıbbi kayıt ve hasta dosyaları kayıt sisteminin düzenli olması ve verimli çalışması, bu konuda mesleki eğitim almış sağlık çalışanları (Tıbbi Dokümantasyon ve Sekreterlik Programı mezunları) ile doğrudan orantılıdır. Sağlık hizmetleri ileri teknolojinin kullanıldığı, hekimler, hemşireler, teknisyenler, terapistler, yöneticiler, tıbbi sekreterler ve diğer sağlık çalıșanlarının kapsamlı ve koordineli bakım sağlama görevini üstlendiği emek yoğun bir sektördür. Tıbbi sekreterler sağlık ekibinin bir parçası olarak hastanın hastaneye başvurmasından taburcu işlemlerinin yapılmasına kadar olan bütün aşamalarda birçok farklı görevi üstlenmektedir. Bu çalışmada Türkiye'de Tıbbi Dokümantasyon ve Sekreterlik Eğitimi, Mesleki uygulamalar incelenmiştir.
\end{abstract}

Anahtar Kelimeler: Tıbbi Dokümantasyon ve Sekreterlik, Tıbbi Sekreter, Tıbbi Sekreterlik Eğitimi

\begin{abstract}
Communication and information / document concepts are important concepts that complement each other and are not separated from each other. (It is a basic duty of medical secretary.)In order to make effective use of documents; According to scientific principles and rules of documents; collection, arrangement, storage and return to service. That is, it must be subject to documentation activities.Regular and efficient operation of the medical records and patient files registry system is directly proportional to vocationally trained health workers (Medical Documentation and Secretarial Program graduates).Health care service is the labor intensive sector that is used advanced technology and assumed comprehensive and coordinated care by physicians, nurses, technicians, therapists, administrators, medical secretaries and other health care professionals. Medical secretaries regarding one of the member of the health care team assume a lot of different tasks from the patients apply for the hospitals to discharge processing.In this study, Medical Documentation and Secretarial Training in Turkey, Professional practices are examined.
\end{abstract}

Keywords: Medical Documentation and Secretary, Medical Secretary, Medical Secretary Training 


\section{Giriş}

İçinde bulunduğumuz çağa kimi zaman "İletişim çă̆ı", kimi zaman "Bilgi çă̆ı" denildiğini biliyoruz. İletişim ve bilgi / belge kavramları birbirini tamamlayan ve birbirinden ayrılmayan önemli kavramlardır. (Tıbbi sekreterliğin temel görev alanlarındandır.)Bilgi, insanlığın başlangıcından beri toplumların gelişmesinde en önemli unsur olmuştur. Bilgi insanlı̆ğın en değerli hazinesidir. Günümüzde toplumsal yaşamın her aşamasında bilgiye olan ihtiyaç artmaktadır. Bu nedenle bilgiyi teknoloji ile daha etkin kullanabilecek imkânlar oluşturulmalıdır. En geniş anlamda belge, eldeki verilerin ve bilginin kaydedildiği değişik kayıt ve yayın türlerine verilen addır. İnsanların çeşitli amaçlarla yaptıkları çalışmalardan elde edilen bilginin düzenli bir şekilde kayıt edildiği bilgi kaynaklarına doküman denilmektedir.

\section{Belgeleri Kimler Kullanır?}

Belgeleri; Kurum yöneticileri, kurum çalışanları ve toplumun diğer tüm bireyleri kullanır.

\section{Belgelerin Özellikleri Nasıl Olmalıdır?}

Belgeler:

- İhtiyaç duyulan nitelik ve nicelikte,

- İstenilen zamanda,

- İstenilen yerde,

- Doğru bilgiyi içerir şekilde olmalı ve sunabilmelidir.

Sağlık kurumlarında bu görevler; Tıbbi Dokümantasyon ve Sekreterlik mezunlarınındır. Belgelerden verimli şekilde yararlanılabilmesi için; belgelerin bilimsel ilke ve kurallara göre; toplanması, düzenlenmesi, saklanması ve tekrar hizmete sunulması gerekir. Yani dokümantasyon faaliyetlerine tabi tutulması gerekir. Bu anlamda belge ile dokümantasyon faaliyetleri arasında sıkı bir iş birliği vardır. İstenilen bilgi ve belgelere kolay ulaşılabilmesi için dokümantasyon faaliyetlerinin bilimsel ilke ve kurallara göre yapılması gerekir.

İçinde bulunduğumuz bilgi çağının gereği olarak; özellikle sağlık alanında; bilginin

- Üretilmesi,

- Kullanımı,

- Yönetimi ve

- Değerlendirilmesi giderek artan bir oranda önem kazanmaktadır.

Sağlık hizmetlerinde etkin bir hizmet sunumu için sistematik olarak bilginin elde edilmesi, kayıt edilmesi ve saklanması zorunludur. Bunun içinde düzenli ve kaliteli bir bilgi kaylt sisteminin olması gerekir. Dünyada, sağlıkla ilgili bilginin kaydı ve saklanması işlemleri (tıbbi dokümantasyon işlemleri); tıbbi dokümantasyon ve sekreterlik bölümlerinden veya benzer eğitim alanlarından mezun olanlar tarafından yapılmaktadır. Tıbbi kayıt ve hasta dosyaları kayıt sisteminin düzenli olması ve verimli çalışması ise, Bu konuda mesleki eğitim almış sağlık çalışanları (Tıbbi Dokümantasyon ve Sekreterlik Programı mezunları) ile doğrudan orantılıdır.

Hastanede verilen hasta bakım ve tedavi hizmetinin kalitesini yükseltmede;

- Tibbi kayitların doğru tutulması

- Zamaninda tutulmasi

- İhtiyaç duyulduğunda hizmete sunulmasi gerekir.

Hastalıkların, uluslararası sınıflandırılması sistemine göre (ICD) kodlanması TİG (Tanı İlişkili Grup) için özellikle önemlidir. Doğru kod için doğru dokümantasyon gerekir. Bunun çözümü ise tıbbi dokümantasyon ve sekreterlik programı mezunudur. 


\section{Tıbbi Dokümantasyon ve Sekreterlik Eğitimi}

Günümüzde sağlık hizmetleri; farklı mesleklerin bir arada, kaliteli hasta bakım ve tedavi hizmeti sunmak için yüksek teknolojik imkânlardan azami şekilde yararlanarak sunulan bir ekip hizmetidir. Tıbbi sekreterler sağlı ekibinin bir üyesi olarak, hastanın hastaneye kabulünden taburcu oluncaya kadarki tüm aşamalarda birçok görevi üstlenmektedir. Tıbbi sekreterlik, tıbbın ve hasta kayıtlarının gelişimine paralel bir geçmişe sahiptir. Bu anlamda toplumsal ve teknolojik gelişmeler doğrultusunda tıbbi sekreterlikte de önemli değişiklikler ve gelişmeler görülmüştür. Çağımız sağlık hizmetlerinde bilgiye olan talebin artması ile tıbbi dokümantasyon ve sekreterlik alanında birtakım farklı yaklaşımlar ve uygulamaların ortaya çıktığ 1 görülmüştür. Hastanelerde bilgisayar teknolojisinin kullanılmasında sağlanan gelişmeler, tıbbi sekreterlik mesleğinin yerine getirilmesinde hız ve kalite bakımından önemli katkılar sağlamıştır. Tıp sekreterliği, diğer sekreterliklerden uzmanlık yönüne verilen önem bakımından ayrılmaktadır. Hastane, klinik ve laboratuvarlarda tıp sekreterliklerinin uzmanlık bilgilerine büyük gereksinim duyulmaktadır (Tutar, 2002).Özellikle ülkemizde kullanılan tıbbi sekreter kavramının; literatürde ve gelişmiş ülkelerdeki uygulamalarda, birden çok kavramla ifade edildiği görülmektedir. Bunlar tıbbi kayıt görevlisi, tıbbi transkripsiyonist, tıp sekreteri, yönetici tıbbi asistan, kodlayıcı, hasta kabul görevlisi, resepsiyonist, tıbbi kayıt teknisyeni ve sağlık bilgi teknisyeni olarak tanımlanmaktadır (Demir, 2008).Yurt dışında oldukça eski bir geçmişe sahip olan (1912) tıbbi dokümantasyon ve sekreterlik mesleğinin Türkiye'deki gelişimi oldukça yenidir. 1974 yılında Hacettepe Üniversitesi Sağlık Teknolojisi Yüksekokulu'nun 5 bölümünden birisi olarak açılan Tıbbi Sekreterlik Bölümünde Türkiye'deki ilk tıbbi sekreterlik eğitimi verilmiştir. 1974-1975 yılları arasında 34 tıbbi sekreterlik öğrencisi ile eğitim veren bölüm ve okulun diğer bölümleri aynı yıl üniversite tarafından kapatılmıştır. Tibbi sekreterlik bölümünde 1 y1l eğitim gören öğrencilerden 14'ü Hacettepe Üniversitesinde dört y1llık lisans eğitimi vermek için aynı yıl açılan Hastane İdaresi Yüksekokulu'na 2. sınıftan başlatılmıştır. Bu öğrenciler okulun ilk öğrencileri olmuştur. Türkiye'de ilk tıbbi dokümantasyon ve sekreterlik programı 2547 sayıl1 YÖK Kanununun 7. maddesinin d fikrası uyarınca 04.02.1984 tarih ve 85.12.153 sayıl1 kararla 7 programlı olarak açılan Hacettepe Üniversitesi Sağlık Hizmetleri Meslek Yüksekokulu içerisinde iki yıllık bir program olarak açılmıștır. Daha sonra Ankara Üniversitesinde 1988-1989 öğretim yılında Sağlık Hizmetleri Meslek Yüksekokulu bünyesinde Tibbi Dokümantasyon ve Sekreterlik programı açılmıştır (Esatoğlu, Artukoğlu, 2000).Tıbbi Dokümantasyon ve Sekreterlik programı 147 üniversitede bulunmaktadır. Bunlardan kırkyedisi ikinci öğretim, on biri uzaktan öğretim, ikisi Açık Öğretim, otuz biri özel üniversitedir. Tüm bu yüksekokullardaki toplam öğrenci kontenjanı 2015 OSYM kılavuzuna göre 13644 dür (Tengilimoğlu, Köksal,2016).Üniversitelerin T1bbi dokümantasyon ve sekreterlik programlarına ÖSYM sınavları ile YGS3 puan türüne göre öğrenci alınmaktadır.

Üniversitelerin Sağlık Hizmetleri Meslek Yüksekokulu Tıbbi Dokümantasyon ve Sekreterlik Programı

\section{Amacı}

Sağlık kurum ve kuruluşlarının tıbbi dokümantasyon ve sekreterlik alanında ihtiyaç duyduğu tıbbi sekreterleri yetiştirmektir.

\section{Tıbbi Dokümantasyon ve Sekreterlik Programı Mezunlarının Unvanı}

TDS Programını bitirenlere Ön Lisans diploması ve YÖK Yürütme Kurulunun 27.07.1992 tarih ve 92.26.698 sayılı kararı gereğince, Sağlık Teknikeri (Tıbbi Sekreter) unvanı verilmektedir.

\section{Tıbbi Dokümantasyon ve Sekreterlik Programı Mezunlarının Görev Tanımı}

T1bbi sekreter, tıbbi dokümantasyon ve sekreterlik alanında ön lisans eğitimi verilen yüksekokullardan mezun; hastanın sağlık kuruluşuna gelişinden taburcu oluncaya kadar geçen süreçte hastaya ait tıbbi kayıtları bilimsel ilke ve kurarlara göre tutan, dosyalayan, arşivleyen, hastalıkların uluslararası sınıflandırma sistemine göre kodlama işlemlerini yapan ayrıca idari ve tıbbi ünitelerin haberleşme ve yazışma işlerini yapan mesleki eğitim almış sağlık personelidir. Ülkemizdeki sağlık hizmetleri meslek yüksekokullarındaki diğer tıbbi dokümantasyon ve sekreterlik programlarının amaçları incelendiğinde; amaçlar itibariyle benzerlikler olmakla birlikte aralarında çok ciddi farklılıkların olduğu görülmektedir. 


\section{Tıbbi Sekreterin Görev Yetki ve Sorumlulukları}

- Hastanın randevu hizmetlerini düzenler

- Hasta kabul işlemlerini yapar

- Hastayi kurumun işleyişi ve tıbbi hizmetler konusunda bilgilendirir

- Hastaya ait tıbbi kayitları tutar

- İdari ve tıbbi ünitelerdeki haberleşme ve yazışma hizmetlerini yürütür

- Hasta dosyalarını ve gerekli görülen diğer belge ve raporları bilimsel metotlarla dosyalayarak arşivler ve gerektiğinde tekrar hizmete sunar (Tibbi dokümantasyon faaliyeti)

- Hastalıkları-işlemleri ve sağlıkla ilgili sorunları belirlenen, hastalıkların uluslararası sinıflandırma sistemlerine göre kodlama işlemlerini yapar

- Tıbbi istatistikler ile ilgili verileri toplar ve bilimsel metotlarla analiz ederek sonuçları periyodik olarak ilgililere rapor eder.

\section{Tıbbi Sekreterlik Eğitiminin Süresi ve İçeriği}

Sağlık Hizmetleri Meslek Yüksekokullarının Tıbbi Dokümantasyon ve Sekreterlik programı liseden sonra 2 yıl, Sağlık Meslek Lisesi Tıbbi Sekreterlik bölümü ise ilköğretimden sonra 4 yıldır.

\section{Tıbbi Dokümantasyon ve Sekreterlik Programı}

Birinci yılında: Tıbbi dokümantasyon, tıbbi terminoloji, on parmak klavye kullanımı, tıbbi terminoloji, bilgisayar teknolojileri, halkla İlişkiler, sağllk bilgi sistemi, biyoistatistik, sağllk hizmetleri yönetimi, anatomi, halkla ilişkiler, temel bilgi teknolojileri İngilizce, Türk dili ve Atatürk ilkeleri ve inkılap tarihi okutulmaktadır.

İkinci yılında: Tıbbi dokümantasyon, psikolojiye giriş, on parmak yazım teknikleri, araştırma teknikleri tıp kütüphaneciliği, hastane bilgi sistemleri, hastalıkların uluslararası sınıflandırılması, halk sağlığı ve tıbbi deontoloji, tıbbi sekreterlik teknikleri, hastalıklar bilgisi, bilgisayarda dizgi tasarım, güzel konuşma, dosyalama ve arşivleme dersleri okutulmaktadır. Birinci ve ikinci sınıfta toplan 938 saat teorik (\%51.54), birinci ve ikinci sınıfta (stajlar dahil) 882 saat pratik (\%48.46) yapmaktadırlar. Mezunlar 1820 saat ders almaktadırlar. Alınan derslerin \%87.3'ünü mesleki dersler oluşturmaktadır.

\section{Mezuniyetle Kazanılan Bilgi ve Beceriler}

Konuşma, dinleme, giyim, protokol kuralları, işe motive olma, yöneticiyle çalışma, hasta ve sahipleriyle etkili ve düzenli iletişim kurma, tıbbi kayıt sisteminin düzenlenmesi ve etkin kullanımı, diksiyon, dosyalama ve arşivleme teknikleri, kodlama için esas olan tıbbi kayıtlardan ICD-10 sistemini kullanarak kodlama yapabilme, iş yazıları ve resmi yazışmaların hızlı ve düzenli yapılması konularında bilgi ve beceri kazanırlar. Çok iyi bilgisayar ve klavye kullanım becerisine sahip olan mezunlar ayrıca meslekleri ile ilgili grafik, dizgi, tasarım konularında da bilgi ve beceriye sahip olmaktadırlar.

\section{İstihdam İmkânları}

Mezunlar; özel ve kamu sağlık sektöründe çalışmaktadırlar. Kamu sektöründe KPSS sınavı sonuçlarına göre mezunlar tercih yapmakta ve yaptıkları tercihler sonucu atamaları yapılmaktadır. 2016/7 KPSS alımında Tıbbi Dokümantasyon ve Sekreterlik bölümü mezunları içerisinde en düşük puan 82,2 puan iken, en yüksek 86,7 taban puanla atanmıştır. Sağlık Personeli olarak KPSS 2016/7 sözleşmeli alımlarında önlisans mezunu olan tıbbi dokümantasyon ve sekreterlik bölümü mezunları için açılan "Sağlık Teknikeri Kadro sayısı 204" olarak belirlenmiştir. (KPSS 2016/7 Tercih Klavuzu) Kamuya ait sağlık kuruluşlarının klinik, poliklinik, laboratuar, ameliyathane, acil servis gibi tıbbi birimler yanında sağlık kurulu, hasta kabul, hasta dosyaları arşivi, personel, döner sermaye, satın alma gibi idari birimlerde de görev yapmaktadırlar. Özel sektörde, özel hastaneler, özel sağlık merkezleri, özel laboratuar, özel muayenehane, eczane, özel radyoloji merkezleri, ecza depoları ve yazılım firmalarında çalışmaktadırlar. Sağlık hizmetlerinde yaşanan hızlı değişime paralel olarak, bu programı bitirenlere 
özel ve kamuya ait tüm sağlık kurum ve kuruşlarında talep giderek artmakta ve mezunlara geniş iş imkânı bulunmaktadır.

\section{Dikey Geçiş İmkânı}

Üniversitelerin sağlık kurumları işletmeciliği, sağlık kurumu yönetimi, sağlık idaresi lisans bölümleri ve sağlık yönetimi alanlarına dikey geçiş imkânı bulunmaktadır. Sınavsız olarak AÖF işletme bölümünde lisans tamamlama imkânları vardır.

\section{Orta Öğretimde (Anadolu Sağlık / Sağlık Meslek Liselerinde) Tıbbi Sekreterlik Öğretimi}

Türkiye'de tıbbi sekreterlik mesleği, 1980'li yılların öncesine dayanmaktadır. O yıllarda, bu kadroya, eğitim almadan seçilen memurlar atanmaktaydı. Eğitim veren okullar 1994 y1lında eğitime başlanmasına rağmen 1982' de yayınlanan Sağlık Bakanlığı Yataklı Tedavi Kurumları İşletme Yönetmeliğinin 160. maddesinde tıbbi sekreterin görevleri belirtilmiştir. Tibbi Sekreter MADDE: 160 - Lise veya dengi okul mezunu daktilo bilir personeldir. Hasta müşahede kâğıtlarını, tıbbi raporları ve tıbbi mesleki mektupları tabiplerin söyledikleri şekilde ve usulüne uygun olarak daktilo ile yazar. Tabipler tarafından teyp, pikap ve diğer kayıt cihazlarına söylenenleri deşifre eder. Bilimsel toplantılarda konuşulanları not alır. Gerektiğinde hasta müşahede kâğıtları ve raporların örneklerini çıkartır (Sağlık Bakanlığı, 1983). Sağlık enformasyon ve dokümantasyon hizmetlerinin istenilen düzeyde yürütülmesi ve sağlik hizmetlerinde verimliliğin olumlu şekilde etkilenmesi amaciyla sağlik meslek liselerinin mevcut bölümlerine ilave olarak makamın 25.02.1994 tarih ve 1412 sayılı onayı ile “Tıbbi Sekreterlik" bölümü açılmış ve 1994-1995 öğretim y1lında 22 okulda eğitim öğretime başlanmıştır. 2009 yılı itibariyle sadece Sağlık Bakanlığı bünyesinde 4000 civarında tıbbi sekreter çalışmaktadır (http://megep.meb.gov.tr/mte_program_modul/modul_pdf/346SBI025.pdf).

\section{Mesleki Sorunlar}

Tıbbi dokümantasyon ve sekreterlik program mezunlarının meslek tanımı açık ve net bir şekilde yapılmamıştır. Net bir tanımın ve iş analizinin olmaması uygulamada çalışanlar ile yöneticiler arasında ciddi problemlere neden olmaktadır. Göreve yeni başlayan tıbbi dokümantasyon ve sekreterlik mezunları; kurum yöneticisinin tıbbi sekreterliği algılamasına göre farklı bölümlerde ve farklı işlerde çalışmaktadırlar. Akademik olarak tıbbi dokümantasyon ve sekreterlik programının bulunan sağlik hizmetleri meslek yüksekokullarında programların amaçları belirtilmiş (birbirlerinden tamamen farklı bir şekilde her TDS programı) ancak net ve ortak bir meslek tanımı (tıbbi sekreterlik) yapılmamıştır. Kamu sağlık kurumlarına KPSS sonuçlarına göre işe giren mezun sayısı yıllık mezun sayısına göre oldukça düşüktür. (önlisans yaklaşık 4000 kişi, lise 1000 kişi mezun oluyor. Açılan kadro 700-800 kişi) Önlisans mezunlarından üniversite hastanelerinde çalışanların bazıları sağlk hizmetlerinden maaş alması gerekirken genel idare hizmetleri sınıfından maaş alıyorlar bu durumda onları emsallerine göre mağdur etmektedirler. Meslek edindirme kursları, sertifika eğitimleri (halk eğitim merkezleri, özel kurslar, üniversitelerin sürekli eğitim merkezleri, iş kur/ Avrupa birliği projeleri) mesleki eğitim almış meslek mensubunun istihdamını engellemekte ve okuyan öğrencilerin motivasyonunu kırmaktadır. Milli Eğitim Bakanlığının 10.09.2010 tarih ve 4611 sayılı 2009/69 Genelgenin 6. maddesinde " $\underline{S a \breve{g} l l k}$ meslek liselerinde ĕgitim-öğretimi yapılan alan/dallar ile tanımları özel kanunlarla düzenlenmis meslek alan/dallarında, geliștirme ve uyum kursları dıșında meslek kursu açılmaması," kararı bulunmaktadır. Ancak uygulamada birçok özel ve kamu kuruluşu isim değişikliği ile halen kurs açmaktadırlar (hasta kayıt elemanı, veri giriş elemanı vb.). Kamu sağlık kuruluşları özellikle hizmet alımlarında mesleki eğitim almış tıbbi sekreterleri çalıştırmak yerine kurs belgesi almış hatta hiç belgesi olmayanları tıbbi sekreter olarak çalıştırmaktadırlar. Özel sektör de iş imkânı var gibi görünse de çoğu zaman asgari ücretle ve almış olduğu eğitimle doğrudan ilgili olmayan alanlarda da çalıştırılarak iş imkânı verilmektedir. Özel sektörde maddi yetersizliklerle birlikte her an işten çıkarılma ihtimalinin yüksekliği çalışanı mutsuz ve başarısız etmektedir. Mesleki örgütlenmeye geç başlanılması ve kurulan derneğin mezunlar tarafindan bilinmemesi örgütsel bağlılığ 1 ve meslekleşme bilincinin oluşturulmasını geciktirmektedir. Üniversitelerde sağlık hizmetleri meslek yüksekokullarında bir program açılması 
istendiğinde açılması ilk akla gelen program tıbbi dokümantasyon ve sekreterlik programıdır. Gerekli alt yapı ve özellikle bu konuda çalışan öğretim elemanlarını istihdam etmeden çok ilgili olmayan alanlardaki kişilerin öğretim elemanı olarak görevlendirilmesi verilen tıbbi dokümantasyon ve sekreterlik öğretiminin kalitesini düşürmektedir. Öğretim elemanı kaynağındaki niteliksel ve niceliksel yetersizlikler sağlık meslek lisesine atanacak öğretmenler içinde geçerlidir. Meslek lisesindeki derslerde konuya uzak kişiler tarafindan verilmektedir.

\section{Sonuç ve Öneriler}

Meslek tanımı, iş analizi, yetki sorumluluklar çağın gerekleri ve bilimsel ilkelere göre sektörel beklentiler de dikkate alınarak yetkili kurumlarca yapılmalıdır. Yapılan bu çalışmanın sonucu özel sektörü de bağlayıcı olmalıdır. Tüm mezunlar sağlık hizmetleri sınıfında değerlendirilmelidir. $\mathrm{Bu}$ anlamda ekonomik kayıplarının giderilmesi sağlanmalıdır. Tıbbi dokümantasyon ve sekreterlik alanına yakın bölümlerden mezun olanların öğretim elemanı olarak bu programlarda istihdam edilmesi konusunda hassas davranılmalıdır. Özellikle kamudaki istihdam oranları artırılmalı ve daha çok mezunun işe girmesi sağlanmalıdır. Meslek edindirme kurslarının açılması kesinlikle engellenmelidir. Hizmet alımlarında tıbbi sekreterlik mezunlarının tercih edilmesi için yasal düzenlemeler yapılmalıdır. Meslekleşmenin hızlanması için mesleki örgütlenme (mezunlar derneği vb.) mezunlar tarafından desteklenmelidir. Tibbi dokümantasyon ve sekreterlik, tıbbi kayıt yönetimi vb. konularda tıbbi dokümantasyon ve sekreterlik programları ortak sempozyumlar, kongreler düzenlenmeli ve dergi çıkarmalıdırlar. Mesleği sahada başarılı bir şekilde temsil eden mezunların tecrübelerinden yararlanmak için belirli aralıklarla öğrencilerle tanışma toplantıları, söyleşiler yapılarak öğrencilerde meslek bilincinin oluşturularak güçlendirilmesi sağlanmalıdır. Özellikle hastane bilgi sistem programlarının tanıtımı için farklı firmaların okulda program demosu yapması sağlanmalıdır. Meslek sorunlarının tartışılıp çözüm önerilenin sunulduğu, mesleki dayanışma ve işbirliğinin sağlanması amacına yönelik olarak daha yoğun bir şekilde bilimsel aktiviteler yapılmalı ve öğrencilerin bu aktivitelerde etkin rol almaları sağlanmalıdır.

\section{Referanslar}

ARTUKOĞLU, A., KAPLAN, A., YILMAZ, A., (2000). Tibbi Dokümantasyon. Ankara: Kum Matbaas1

DEMİR Ö., (2008). "Tıbbi Sekreterlik Mesleğinin Gelişimi ve Sağlık Hizmetlerindeki Rolü" Geçmişten Geleceğe Sağllk Teknikerliği. (kitabının içinde)Sağlık Teknikerliği Konusunda Bilimsel Çalışmalar Türkiye. Onur Matbaacılık.

ESATOĞLU, E. A., ARTUKOĞLU, A., (2000). T1bbi Dokümantasyon Tarihi ve Tibbi Dokümantasyon İle İlgili Meslekleşmenin Gelişimi, Ankara Üniversitesi Dikimevi Sağlık Hizmetleri Meslek Yüksekokulu Yıllığı Cilt 1 Sayı 1.

TENGILIMOĞLU, D., KÖKSAL, A. (2016). Yönetici ve T1p Sekreterliği. Ankara, Seçkin Yayıncilik.

TUTAR, H., (2002). Yönetici Sekreterliği. Ankara: Nobel Dağıtım.

"Yataklı Tedavi Kurumları İşletme Yönetmeliği” Sağlık Bakanlığı, (1983). 13 Ocak 1983 tarih ve 17927 sayılı Resmi Gazete. 05 Mayıs 2005 tarih ve 25806 sayılı Resmi Gazete'de yapılan değişiklik yayımlanmıştır.

www.meb.gov.tr.

http://megep.meb.gov.tr/mte_program_modul/modul_pdf/346SBI025.pdf

www. sagl1k.gov.tr.

KPSS 2016/7 Tercih Kılavuzu

www.osym.gov.tr 